OPEN ACCESS

International Journal of Management \& Entrepreneurship Research

P-ISSN: 2664-3588, E-ISSN: 2664-3596

Volume 4, Issue 1, P.No. 59-73, January 2022

DOI: 10.51594/ijmer.v4i1.288

Fair East Publishers

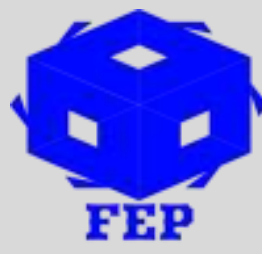

Journal Homepage: www.fepbl.com/index.php/ijmer

\title{
MARKETING STRATEGIES AND PASSENGERS' ADOPTION OF RIDE-HAILING SERVICES
}

\author{
Dr. Samuel Etuk ${ }^{1}$, Edim Eka James ${ }^{2}$, Dr. Uduak E. Joseph ${ }^{3}$ \\ ${ }^{1}$ Department of Marketing, University of Uyo, Nigeria \\ ${ }^{2}$ Department of Marketing, University of Calabar, Nigeria \\ ORCID: 0000-0002-1728-3831 \\ ${ }^{3}$ Department of Marketing, University of Uyo, Nigeria
}

Corresponding Author: Edim Eka James

Corresponding Author Email: jamesedim@gmail.com

Article Received: 03-01-22

Accepted: 20-01-22

Published:30-01-22

Licensing Details: Author retains the right of this article. The article is distributed under the terms of the Creative Commons Attribution-Non Commercial 4.0 License (http://www.creativecommons.org/licences/by-nc/4.0/), which permits non-commercial use, reproduction and distribution of the work without further permission provided the original work is attributed as specified on the Journal open access page.

\begin{abstract}
This study examined marketing strategies and passengers' adoption of ride-hailing services. Its specific aim was to assess the influences of marketing communication, service quality, relationship marketing, and E-marketing strategies on passengers' adoption of ride-hailing services. The study adopted a cross-sectional survey research design. A structured questionnaire was adapted to obtain primary data from 277 passengers of Bolt ride-hailing service, while multiple linear regression was adopted to test the hypotheses developed for the study. Consequently, the study found that relationship marketing strategy had the highest significant positive effect on passengers' adoption of ride-hailing services, followed chronologically by E-marketing, service quality, and marketing communications. Therefore, the study concluded that marketing strategies have a significant and positive influence on passengers' adoption of ride-hailing services. The study further made practical implications and provided an agenda for future research.
\end{abstract}

Keywords: Marketing Strategies, Passengers’ Adoption, Ride-Hailing, Ride-Sharing. 


\section{INTRODUCTION}

The evolution and continuous development of modern technologies have brought about revolutionary changes in several aspects of human endeavor, including business operations. As a consequence, business organizations in virtually every sector or industry have witnessed innovations that have transformed the processes and manner in which business operations are executed (Christa \& Kristinae, 2021). In the transportation industry, Suhud (2021) observed that mobile communications technologies have made it easier and more convenient for passengers to obtain transportation services they require even without leaving their homes, thereby bridging the spatial gaps between companies and passengers. This has led to the growth of an innovative form of passenger transportation service known as "ridehailing", which involves passengers using designated websites or mobile application software to hire personal drivers to convey them to their desired destinations. As of 2020, the global ride-hailing industry was worth about US\$ 73.5 billion (Precedence Research, 2021). The industry appears to be growing rapidly at a compound annual growth rate (CAGR) of 16.7 percent between 2021 and 2030, where it is projected to increase its market worth to about US\$ 344.4 billion (Statistica, 2021). By almost every measure, the global ride-hailing industry is growing by leaps and bounds as evidenced in the proliferation of their services to countries and cities in virtually every corner of the world, including developing countries, where operators are penetrating new markets for development and competitive advantages. According to Man, Ahmad, Kiong, and Rashid (2019), the growth and proliferation of ride-hailing service companies around the world is fueled in part by mobile technological innovations and the competitive marketing strategies adopted by these companies.

In the views of Wakhu and Bett (2019), marketing strategy is an organized set of plans detailing the procedures, methods, and schemes a company will adopt to pursue and achieve its marketing goals and objectives. It is designed, implemented, and controlled by companies as a means to realizing their established or desired marketing objectives such as sales growth, market penetration and customer patronage. Ang'asa (2017) argued that ride-hailing companies around the world have exploited a variety of competitive marketing strategies in a push to improve their performance. Companies such as Uber, Lyft, Juno, Grab and Bolt apply marketing strategies such as internet marketing (social media, mobile marketing, and email marketing); telemarketing, marketing promotion, relationship marketing, reputation marketing and a host of others in their daily operations. However, this study was concerned with exploring how ride-hailing service providers have applied marketing communication, service quality, relationship marketing and E-marketing in a bid to encourage passengers' adoption of their services. Marketing communications entails a process whereby ride-hailing companies communicate with potential and actual passengers to persuade and encourage adoption and/or patronage of their services (Alhawamdeh, 2021). Service quality is the difference between expected service performance and actual performance of ride-hailing services resulting in either passengers' satisfaction or dissatisfaction (Man, Ahmad, Kiong \& Rashid, 2019).

Relationship marketing involves ride-hailing companies establishing, promoting and maintaining cordial and mutually-useful relationships with passengers to promote passenger 
retention. Whereas, E-marketing is the adoption or utilization of the internet and internetenabled devices or platforms to promote and deliver ride-hailing services to passengers (Etim, James, Arikpo \& Okeowo, 2021). Even though these marketing strategies have been adopted by ride-hailing companies to advance their marketing processes, there is however inadequate empirical evidence of their influence on passengers' adoption of ride-hailing services. This entails that the extent to which these marketing strategies have influenced passengers' adoption behaviour towards ride-hailing services is yet to be definitively clarified by existing research.

This has resulted in a series of scholarly studies aimed at exploring the influence of marketing strategies on the performance of business organizations around the world, including ridehailing companies. However, it has been observed that the vast majority of studies on this subject have centered on small and medium-sized enterprises (SMEs) (Ebitu, 2016; Mustapha, 2017; Akinitire, Segundayo \& Oluwatobi, 2018; Yalo, Enimola \& Nafiu, 2019; Anne, 2020); fast-moving consumer goods (Ataman, Van Heerde \& Mela, 2017); hotels (Korir, 2020); and commercial banks (Haran \& Yusuf, 2013). The influence of marketing strategies on the marketing performance of ride-hailing companies has received minimal research attention by scholars around the world despite the growing prominence of ridehailing services in today's society. Even among the few existing studies available on ridehailing services, the empirical scope has been narrowed to just competitive marketing strategies such as product differentiation, cost leadership, focus strategy and service quality, out of the variety of marketing strategies currently adopted by ride-hailing companies. The implication of these research gaps is that there is insufficient empirical evidence to comprehensively demonstrate and explain the roles of marketing strategies in influencing the marketing performance of ride-hailing services, specifically its influence on passengers' adoption of the services. This study was therefore initiated to examine the effect of marketing strategies (marketing communication, service quality, relationship marketing and Emarketing) on passengers' adoption of ride-hailing services to provide practical implications to ride-hailing service operators; and empirical implications for further studies.

\section{LITERATURE REVIEW}

\section{Ride-Hailing Services}

Ride-hailing services are transportation services that involve passengers using designated websites or mobile application software to hire personal drivers to convey them to their desired destinations (Suhud, 2021). Ride-hailing or sharing companies utilize global positioning systems (GPS), the internet and smartphones to connect independent personal drivers to passengers who have them conveyed from one place to another for a fee. In most parts of the world, ride-hailing has been a popular means of intra-city transportation for passengers, whereas, in developing parts of the world, such as Africa, it is increasingly becoming a comfortable alternative to the conventional public transportation systems that are often overcrowded and riddled with discomfort (Gaber \& Elsamadicy, 2021).

Some of the notable global ride-hailing brands include: Uber, Bolt, Grab, Lyft, Juno, Via, Curb, Gojek, Cabify, and Didi-Rider. In the past few years, two of the world's largest ridehailing companies - Uber and Lyft - have been competing closely for dominance over the ride-hailing industry. As of November, 2021, Uber's average sales per passenger reached 
US\$77, constituting a 6-percent growth compared to November, 2019. Similarly, in November, 2021, the average sales per passenger for Lyft grew to $\$ 71$, constituting an 8percent increase compared to November, 2019 (Perri, 2021).

\section{Marketing Strategies}

Marketing strategy is an organized set of plans detailing the procedures, methods and schemes a company will adopt to pursue and achieve its marketing goals and objectives (Wakhu \& Bett, 2019), It is designed, implemented and controlled by companies as a means to realizing their established or desired marketing objectives such as sales growth, market penetration and customer patronage. Tong, Luo and Xu (2020) view marketing strategy as a concise and intentional plan of action designed and implemented by marketing organizations and entities to facilitate the realization of desired marketing goals and aims. It is carefully thought out and designed after considering internal and external organizational factors such as company's resources, products, services, competition, and any other factor that can potentially affect the implementation and success of the organization's strategies. The importance of marketing strategies, especially in competitive and volatile marketing environments, cannot be ignored because they equip firms with the means to achieve their intended marketing aims while keeping competition in check (Pappas, 2016). As such, Purcarea (2019) describes marketing strategies as a set of strategic and tactical plans carefully designed to enable marketing organizations suppress competitive forces, identify market opportunities and harness them to achieve sustainable competitive advantages in their chosen industry.

\section{Marketing Communication and Passengers' Adoption}

Marketing communication entails a process whereby ride-hailing companies communicate with potential and actual passengers to persuade and encourage adoption and/or patronage of their services (Alhawamdeh, 2021). It is an activity in which business organizations develop promotional content which is disseminated to the target audience through a variety of channels with the objective of raising awareness, influencing and persuading customers to patronize their offerings or develop positive attitudes towards the organization's brand. In the views of Luxton, Reid and Mavondo (2015), marketing communication is the intentional and strategic process of identifying a viable target audience for a company's offering, designing and implementing a communication plan for the purpose of attracting customers' attention and encouraging them to purchase and consume the company's products and services instead of competing brands. In their efforts to inform, persuade and influence consumers to adopt, purchase and consume products and/or services, companies harness the potential of various marketing communication strategies, particularly advertising, sales promotion, personal selling and direct marketing (Hänninen \& Karjaluoto, 2017). This viewpoint suggests that marketing communication influences consumers' adoption of products and/or services.

The viewpoint is consistent with the study of Yalo, Enimola and Nafiu (2019), which revealed that promotional strategy had a significant positive effect on the performance (sales and profitability) of small and medium-scale enterprises. The viewpoint is also backed by the study of Heerde and Mela (2017), which revealed that marketing communication had a significant positive effect on the sales volume of fast-moving consumer goods. These 
scholarly revelations have therefore led to the development of the following hypothesis for testing in this study:

$\mathrm{H}_{1}$ : Marketing communication has a significant effect on passengers' adoption of ridehailing services

\section{Service Quality and Passengers' Adoption}

Service quality is the difference between expected service performance and actual performance of ride-hailing services resulting in either passengers' satisfaction or dissatisfaction (Man, Ahmad, Kiong \& Rashid, 2019). In a broad sense, service quality is the result of the comparison by consumers between perceived or anticipated service and the real service performed by the providing company. Under this view, a service is of high quality if the actual service performed by the providing company equals or exceed customers' anticipated or perceived service prior to service encounter. Conversely, the quality of service is poor or low if the actual service performed by the providing company is pales in comparison with consumers' anticipated or perceived service (Hussain, Al Nasser \& Hussain, 2015). The result of a poor quality service consumed by customers is often dissatisfaction in the short to medium term and total brand switch accompanied with negative word-of-mouth communication over the long-term; which highlights the glaring importance for service providers to consistently deliver high-quality services. In the ride-hailing service context, service quality typically entails attributes such as passengers' safety, passengers' comfort, drivers' quality and vehicle quality all of which are vital in determining passengers' perception of the quality level of operators as well as future patronage intentions (Izogo, 2017). This viewpoint suggests that the delivery of high-quality services by ride-hailing companies could positively influence passengers' patronage. The viewpoint corresponds with the study of Haran and Yusuf (2013), which revealed that service quality had a significant positive relationship with corporate performance. The viewpoint is also backed by the study of Man, Ahmad, Kiong and Rashid (2019), which revealed that service quality had a significant relationship and influence on customers' satisfaction towards ride-hailing services. These scholarly revelations have therefore led to the development of the following hypothesis for testing in this study:

$\mathrm{H}_{2}$ : Service quality has a significant effect on passengers' adoption of ride-hailing services

\section{Relationship Marketing and Passengers' Adoption}

Relationship marketing involves companies establishing, promoting and maintaining cordial and mutually-useful relationships with customers to promote customer retention (Payne \& Frow, 2017). Unlike traditional marketing systems that promote one-time transactions with customers; the aim of relationship marketing is to consistently convert one-off transactions to regular business contacts manifested in customer loyalty. As such, companies guided by the relationship marketing compact seek to understand customers' needs and challenges encountered in purchasing and consuming their offerings in order to be in a better position to

consistently satisfy them thereby enhancing odds of achieving customer loyalty (Steinhoff, Arli, Weaven \& Kozlenkova, 2019). Furthermore, Husnain and Akhtar (2015) suggest that companies can build and improve their relationships with customers through service promise fulfillment, delivery of high-quality services, enabling smooth communications with 
customers, providing prompt customer services and effectively handling customers' complaints. In the ride-hailing context, the service provider's relationship with passengers is largely influenced by passengers' interaction with the providing company's drivers, who interface and interact with passengers personally on a steady basis. Therefore, it is possible that passengers' relationships and experiences with drivers might have an influence on their patronage and re-patronage intentions. This assertion suggests that relationship marketing influences customer patronage and repeat patronage intentions towards a company. Therefore, the following hypothesis has been put forward for testing in the study:

$\mathrm{H}_{3}$ : Relationship marketing has a significant effect on passengers' adoption of ridehailing services

\section{E-Marketing and Passengers' Adoption}

E-marketing is the adoption or utilization of the internet and internet-enabled devices or platforms to promote and deliver ride-hailing services to passengers (Etim, James, Arikpo \& Okeowo, 2021). It is a marketing system that is based on and utilizes the internet as well as other electronic devices for marketing purposes. According to Iddris and Ibrahim (2015), emarketing is an innovative form of marketing where contacts and exchange transactions are initiated and concluded over the internet with little or no human contact between companies and customers, particularly in the context of services where no tangible products are offered. E-marketing is the mainstay and major marketing strategy of ride-hailing services because, by operation, ride-hailing services require internet connection and electronic devices such as mobile phones, iPads and tablets to function (Sheikh, Shahzad \& Ishaq, 2017). Supporting the foregoing viewpoint, Lampe, Alatas, Orynka and Saputra (2021) argued that ride-hailing companies such as Uber and Lyft have been particularly effective at using e-marketing tools to promote their services across the globe even as they compete with each other for market dominance. Existing studies have shown that business organizations have been able to substantially improve their marketing performance by applying e-marketing strategies such as social media marketing, email marketing and mobile marketing. This viewpoint is consistent with the study of Anne (2020), which revealed that digital marketing strategies had significant effects on the marketing performance of SMEs. Similarly, the viewpoint is supported by the study of Korir (2020), which revealed that e-marketing strategies had a significant influence on the performance of hotels. These scholarly revelations have therefore led to the development of the following hypothesis for testing in this study:

$\mathrm{H}_{4}$ : E-marketing has a significant effect on passengers' adoption of ride-hailing services

\section{Empirical Review and Model Conceptualization}

Mustapha (2017) conducted a study to determine the influence of marking strategies on organizational performance by obtaining primary data from 200 small scale enterprises within Maiduguri metropolitan using a structured questionnaire, while multiple regression was adopted for hypotheses testing. The study revealed that product quality strategy, pricing strategy, promotional mix strategy and relationship marketing strategy had significant positive effects on performance of small scale businesses. Another study conducted by Akinitire, Segundayo and Oluwatobi (2018) elicited primary data from 258 small and medium-scale enterprises in Lagos using a structured questionnaire, while data analysis was done using Pearson's Product Moment Correlation analysis. The findings of the study revealed that marketing communication strategy, relationship marketing strategy, product 
quality strategy and product diversification strategy had significant positive relationships with the performance of small and medium-scale enterprises. Also, Yalo, Enimola and Nafiu (2019) carried out a study to assess the impact of marketing strategies on organizational performance. The study elicited primary data from 300 small and medium-scale enterprises in Kogi State using a 5-point Likert scale questionnaire, while data analysis was done using descriptive statistics and multiple linear regression. The findings revealed that promotional strategy, product diversification strategy, relationship marketing strategy, product quality strategy and market segmentation strategy had significant positive effects on the performance (sales and profitability) of small and medium-scale enterprises.

Ebitu (2016) carried out a study that focused on assessing the relationship between marketing strategies and organizational performance. The study obtained primary data from 240 small and medium scale enterprises in Akwa Ibom State using a structured questionnaire, while data analysis was executed using Pearson's Product Moment Correlation analysis. Consequently, the study found that product quality strategy and relationship marketing strategy had significant positive relationships with the performance (profitability and market share) of SMEs. Also, Anne's (2020) study elicited primary data from 30 small and mediumsized enterprises in Kenya through a structured questionnaire while hypotheses testing was done using multiple regression. The study found that digital marketing strategies (blogs, search engine optimization, social media, display advertising and website marketing) significantly affected the marketing performance of SMEs. Similarly, Korir (2020) assess the influence of marketing strategies on the performance of hotels by using a semi-structured questionnaire to elicit primary data from 63 hotel employees in Kenya, while data analysis was done using descriptive statistics and multi-variate regression analysis. The study revealed that e-marketing strategies (search engine optimization, social media, mobile marketing and email marketing) had significant influences on the performance of hotels.

Furthermore, Ataman, Van Heerde and Mela (2017) examined the influence of marketing strategies on the sales volume of fast-moving consumer goods. The study obtained primary data from 186 personnel of fast-moving consumer goods manufacturing companies in Penang using a structured questionnaire, while hypotheses testing was executed using multiple regression. The findings of the study revealed that product diversification, marketing communication, product quality and relationship marketing strategies had significant positive effects on the sales volume of fast-moving consumer goods. Also, Haran and Yusuf (2013) examined the relationship between marketing strategies and corporate performance by obtaining primary data from 320 respondents in Cairo using structured questionnaire, while Pearson's Product Moment Correlation was used for hypotheses testing. The study found that marketing strategies (marketing promotion, customer relationship marketing and service quality) had significant positive relationships with corporate performance. Similarly, Ang'asa (2017) examined competitive strategies and performance of ride-hailing service providers by eliciting primary data from 60 passengers of ride-hailing service in Nairobi using a survey questionnaire, while hypotheses testing was done using multiple regression. The findings of the study revealed that focus strategy, cost leadership and product differentiation strategies had significant positive influences on the competitive performance of ride-hailing service providers. 
In addition, Wakhu and Bett (2019) centered on assessing the influence of competitive strategies on the performance of Uber Online Taxi firms by using a structured questionnaire to obtain primary data from 91 operators of Uber Online Taxi firms in Nairobi while regression analysis was adopted for hypotheses testing. Consequently, the study found that focus strategy, cost leadership and product differentiation strategies had significant positive effects on the performance of Uber Online Taxi firms. Similarly, Man, Ahmad, Kiong \& Rashid (2019) examined the role of service quality in enhancing passengers' satisfaction towards ride-hailing services. The study used online and print questionnaires to obtain primary data from 150 passengers of ride-hailing companies in Kuala Lumpur, while hypotheses testing was done using correlation and regression analyses. Consequently, the findings of the study revealed that service quality had a significant relationship and influence on customers' satisfaction towards ride-hailing services. Existing studies reviewed have shown that the application of marketing strategies can significantly enhance customer satisfaction and overall performance of business organizations around the world, including ride-hailing service companies. Therefore, the conceptual model presented in figure 1 has been adapted from existing studies to demonstrate the hypothesized influence of marketing strategies on consumers' adoption of ride-hailing services in the context of this study.

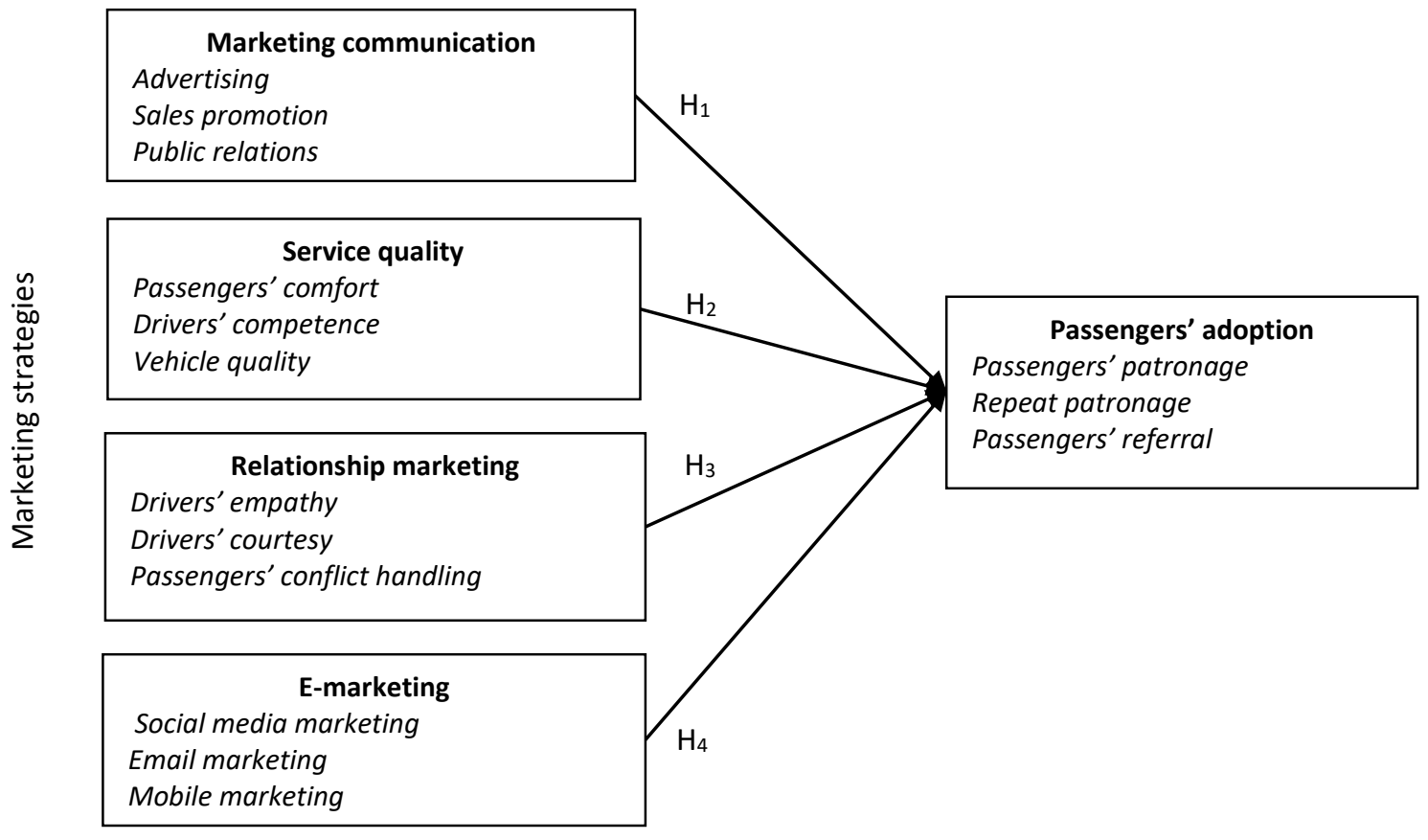

Figure 1: Conceptual model of the study

Source: Independent variables adapted from Akinitire, Segundayo and Oluwatobi (2018); Etuk, Anyadighibe, James and Mbaka (2021); Mustapha (2017); Etim, James, Arikpo and Okeowo (2021); dependent variable adapted from Nwulu and Asiegbu (2015).

\section{METHODOLOGY}

This study was a cross-sectional study which used an adapted structured questionnaire to elicit primary data from a sample of passengers of Bolt in Calabar and Uyo Metropolis, Nigeria at a single period of time. The population of the study therefore comprised all passengers of Bolt in both Calabar and Uyo Metropolis, which was numerically unknown 
due to the absence of publicly-accessible records of all Bolt passengers in the cities. Hence, the study adopted an estimated population of 1000 Bolt passengers, as suggested by Odigbo (2018), who cautioned that an estimated population may be adopted for a study where there are no accessible and valid records of actual population figures. Using the Yamane's (1967) sample size determination procedure (as cited in Adam, 2020), a sample size of 286 passengers was statistically determined for the study. The study therefore used convenience sampling technique to select Bolt passengers to participate in the survey with the assistance of a 3-member team of enumerators. The study relied on primary data obtained from Bolt passengers using a 5-point Likert scale questionnaire with statements adapted from existing studies. The statements measuring marketing communication (statements 1 - 3) were adapted from Akinitire, Segundayo and Oluwatobi (2018); the statements measuring service quality (statements 4 - 6) were adapted from Etuk, Anyadighibe, James and Mbaka (2021); the statements measuring relationship marketing (statements 7 -9) were adapted from Mustapha (2017); the statements measuring e-marketing (statements 10 - 12) were adapted from Etim, James, Arikpo and Okeowo (2021); while the statements measuring passengers' adoption (statements 13 - 15) were adapted from Nwulu and Asiegbu (2015).

The structured questionnaire was checked for validity using content and face validity, while reliability testing was done using the internal consistency approach with the aid of Cronbach's alpha coefficients. The results of the reliability test displayed in Table 1 confirm that the instrument was internally consistent, and hence reliable prior to administration to respondents for the purpose of data collection. To generate findings for the study, the hypotheses developed for this study were tested using inferential statistics (specifically, multiple linear regression) in the SPSS software (version 23). The regression model subjected to statistical testing was stated as follows:

PASSADP $=\mathrm{a}+\beta_{1} \mathrm{MARCOM}+\beta_{2} \mathrm{SQ}+\beta_{3} \mathrm{RM}+\beta_{4} \mathrm{EM}+\mathrm{e}$

Where:

$\begin{array}{lll}\mathrm{PASSADP}= & \text { Passengers' adoption } \\ \mathrm{a} & \text { The intercept (or constant) } \\ \mathrm{MARCOM}= & \text { Marketing communication } \\ \mathrm{SQ}= & \text { Service quality } \\ \mathrm{RM}= & \text { Relationship marketing } \\ \mathrm{EM}= & \text { E-marketing } \\ \beta_{1} \mathrm{MARCOM}= & \text { Coefficient of marketing communication } \\ \beta_{2} \mathrm{SQ}= & \text { Coefficient of service quality } \\ \beta_{3} \mathrm{RM}= & \text { Coefficient of relationship marketing } \\ \beta_{4} \mathrm{EM}= & \text { Coefficient of e-marketing } \\ \mathrm{e}= & \text { Error margin (5 percent) }\end{array}$

Table 1

Instrument Reliability Coefficients 


\begin{tabular}{lcc}
\hline Variables & No. of items & Cronbach's alpha coefficients \\
\hline Marketing communication & 3 & .821 \\
Service quality & 3 & .753 \\
Relationship marketing & 3 & .800 \\
E-marketing & 3 & .773 \\
Passengers' adoption & 3 & .709 \\
\hline \multicolumn{2}{c}{} \\
\hline
\end{tabular}

Source: Authors' Analysis through SPSS 23

\section{DATA ANALYSIS AND DISCUSSION}

Assisted by a 3-member team of enumerators, the study engaged 286 passengers in the questionnaire survey over a period of three weeks. Out of the total of 286 copies of the questionnaire administered, 277 copies (representing 96.9 percent) were retrieved and used for the study, while 9 copies (representing 3.1 percent) were not retrieved. Therefore, the hypothesis testing procedure was based on 277 retrieved questionnaire copies.

Table 2

Model Summary of the Effect of Marketing Strategies on Passengers' Adoption of Ride-hailing Services

\begin{tabular}{ccccc}
\hline Model & R & R Square & Adjusted R Square & Std. Error of the Estimate \\
\hline 1 & $.671^{\mathrm{a}}$ & .451 & .443 & .57443 \\
\hline
\end{tabular}

a. Predictors: (Constant), Marketing communication, service quality, relationship marketing, E-marketing Source: Authors' analysis through SPSS 23

Table 3

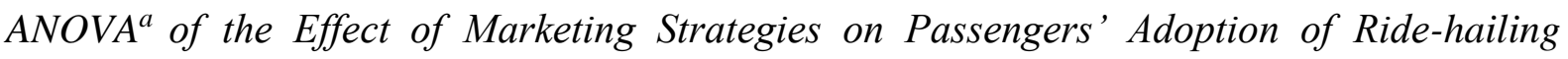
Services

\begin{tabular}{llccccc}
\hline & Model & Sum of Squares & Df & Mean Square & F & Sig. \\
\hline 1 & Regression & 73.617 & 4 & 18.404 & 55.776 & $.000^{\text {b }}$ \\
& Residual & 89.752 & 272 & .330 & & \\
Total & 163.369 & 276 & & & \\
& Total & & & & &
\end{tabular}

a. Dependent Variable: Passengers' adoption

b. Predictors: (Constant), Marketing communication, service quality, relationship marketing, E-marketing Source: Authors' analysis through SPSS 23

Table 4

Coefficients of the Effect of Marketing Strategies on Passengers' Adoption of Ride-hailing Services

\begin{tabular}{|c|c|c|c|c|c|c|}
\hline \multirow{2}{*}{\multicolumn{2}{|c|}{ Model }} & \multicolumn{2}{|c|}{ Unstandardized Coefficients } & \multirow{2}{*}{$\begin{array}{l}\text { Standardized } \\
\text { Coefficients }\end{array}$} & \multirow[b]{2}{*}{$\mathrm{T}$} & \multirow[b]{2}{*}{ Sig. } \\
\hline & & $\mathrm{B}$ & Std. Error & & & \\
\hline \multirow[t]{5}{*}{1} & (Constant) & 1.060 & .321 & & 3.307 & .001 \\
\hline & Marketing communication & .050 & .059 & .143 & 1.854 & .004 \\
\hline & Service quality & .181 & .080 & .318 & 2.270 & .000 \\
\hline & Relationship marketing & .497 & .050 & .471 & 9.926 & .000 \\
\hline & E-marketing & .475 & .059 & .449 & 8.061 & .000 \\
\hline
\end{tabular}

a. Dependent Variable: Passengers' adoption

Source: Authors' analysis through SPSS 23

\section{Interpretation}

Tables 2 to 4 summarize the results of the multiple regression analysis of the effect of marketing strategies on passengers' adoption of ride-hailing services. Judging from the correlation coefficient $(\mathrm{R}=0.671)$ in Table 2 , it can be said that there is a 67.1 percent relationship between marketing strategies and passengers' adoption of ride-hailing services. 
The regression coefficient $\left(\mathrm{R}^{2}=0.451\right)$ also in Table 2 indicates that up to 45.1 percent of the variability in passengers' adoption of ride-hailing services is accounted for by marketing strategies. This entails that marketing strategies influence passengers' adoption of ridehailing services by up to 45.1 percent under normal circumstances. Similarly, the F-statistic $(\mathrm{F}=55.776)$ and the significance level $(\mathrm{p}$-value $=0.000<0.05)$ in Table 3 indicate that the regression model tested is statistically significant, thereby providing credible empirical evidence to conclude that marketing strategies have a significant influence on passengers' adoption of ride-hailing services. Furthermore, the results in Table 4 show that the p-values of all the marketing strategies tested were less than the error margin of 0.05 alongside positive t-values [Marketing communication ( $\mathrm{p}$-value $=0.004<0.05$; $\mathrm{t}$-value $=1.854$ ); service quality ( $\mathrm{p}$-value $=0.000<0.05 ; \mathrm{t}$-value $=2.270)$; relationship marketing $(\mathrm{p}$-value $=$ $0.000<0.05 ; \mathrm{t}$-value $=9.926) ;$ and E-marketing $(\mathrm{p}$-value $=0.000<0.05 ; \mathrm{t}$-value $=8.061)]$. The implication of this result is that marketing communication, service quality, relationship marketing and E-marketing have significant positive effects on passengers' adoption of ridehailing services. However, the variables have varying degrees of effects on passengers' adoption of ride-hailing services as evident in their beta coefficients shown in Table 4. With a standardized beta coefficient of 0.471 (or 47.1 percent), the result indicates that relationship has the highest significant effect on passengers' adoption of ride-hailing services. Emarketing has the second-highest effect on passengers' adoption of ride-hailing services, considering its standardized beta coefficient of 0.449 (or 44.9 percent). Service quality emerged as the third-highest influencer of passengers' adoption of ride-hailing services, given its standardized beta coefficient of 0.318 (or 31.8 percent). Marketing communication was found to have the least effect on passengers' adoption of ride-hailing services, considering its standardized beta coefficient of 0.143 (or 14.3 percent).

From the results of the multiple linear regression above, it was revealed that marketing communication had a significant positive effect on passengers' adoption of ride-hailing services. This finding is similar to the study of Heerde and Mela (2017), which revealed that marketing communication had a significant positive effect on the sales volume of fastmoving consumer goods. The implication of this finding is that passengers' adoption of ridehailing services could significantly be enhanced through the application of marketing communication strategies. The results also revealed that service quality had a significant positive effect on passengers' adoption of ride-hailing services. This finding is similar to the study of Man, Ahmad, Kiong and Rashid (2019), which revealed that service quality had a significant relationship and influence on customers' satisfaction towards ride-hailing services. This implies that ride-hailing companies can improve passengers' adoption of their services by ensuring the delivery of consistently high-quality services to passengers. The results also revealed that relationship marketing had a significant positive effect on passengers' adoption of ride-hailing services. The implication of this finding is that ridehailing companies could significantly improve passengers' adoption of their services by improving their relationships with passengers on a consistent basis. Finally, the results revealed that E-marketing had a significant positive effect on passengers' adoption of ridehailing services. This finding is consistent with the study of Anne (2020), which revealed that digital marketing strategies had significant effects on the marketing performance of SMEs. Similarly, the finding is supported by the study of Korir (2020), which revealed that 
e-marketing strategies had a significant influence on the performance of hotels. The implication of this finding is that passengers' adoption of ride-hailing services could significantly be improved through E-marketing strategies and tools.

\section{CONCLUSION AND PRACTICAL IMPLICATIONS}

As has been identified earlier, the prominence and significant roles played by marketing strategies in commercial enterprises have led researchers around the world to explore the causal relationship between marketing strategies and organizational performance with more emphasis on small and medium-sized enterprises, hotels, commercial banks and less emphasis on ride-hailing services. This has led to a dearth of definitive empirical evidence to explain the roles of marketing strategies in enhancing the performance of ride-hailing operators; which might further undermine the application of marketing strategies by these operators since they are unaware of their significance to marketing performance. Against this backdrop, this study was conducted to assess the influences of marketing strategies (such as marketing communication, service quality, relationship marketing and E-marketing) on passengers' adoption of ride-hailing services. The study sought to determine the effectiveness of these marketing strategies in order to provide insights to ride-hailing operators to enable them encourage the adoption of their services by passengers. As such, the study obtained primary data from passengers of Bolt ride-hailing service using a structured questionnaire. Consequent upon data analysis, the findings of the study revealed that relationship marketing strategy had the highest significant positive effect on passengers' adoption of ride-hailing services, followed chronologically by E-marketing, service quality and marketing communications. The implication of this finding of that ride-hailing companies will find relationship marketing most useful in terms of effectively influencing passengers to adopt their services, followed by E-marketing, service quality and marketing communication. Altogether, the finding implies that passengers' adoption of ride-hailing services could substantially be improved by applying marketing strategies such as relationship marketing, E-marketing, service quality and marketing communications.

Therefore, the study concludes that marketing strategies have a significant and positive influence on passengers' adoption of ride-hailing services. By this, the study provides empirical evidence that demonstrates the roles of marketing strategies in influencing passengers' adoption of ride-hailing services. For ride-hailing service operators, the findings of this study imply that they can better enhance passengers' adoption of ride-hailing services by promoting value-laden and harmonious relationships with passengers at every point of service encounter especially through contacts with drivers. Drivers should be trained to interact and treat passengers with empathy, courtesy and promptly resolve passengers' complaints in a respectful manner in order to provide exciting and remarkable service experiences which will increase the odds of repeat patronage in the long term. The findings of the study also prove that E-marketing can be a useful marketing strategy for influencing the adoption of ride-hailing services. Therefore, operators of ride-hailing services should use innovative E-marketing tools such as social media marketing, email marketing and mobile marketing to communicate with actual and potential passengers in order to encourage ridehailing service adoption. Similarly, the findings imply that service quality is an essential determinant of passengers' continued usage of ride-hailing services; therefore, operators should strive to ensure consistent delivery of high-quality services to passengers by 
improving the quality of their drivers' competence and vehicle quality in order to ensure passengers' comfort during rides. Finally, the findings imply that marketing communication strategies such as advertising, sales promotion and public relations should be applied by ridehailing operators in order to increase the odds of passengers adopting their services.

\section{Limitations and Future Research Agenda}

This study was passenger-centric in data collection and analysis; therefore, it does not explain the roles of marketing strategies in improving the marketing effectiveness of ridehailing operators. It only explored passengers' adoption of ride-hailing services as predicted by marketing strategies. There is therefore need for future studies that center on ride-hailing operators to provide insights into the influence of marketing strategies on their marketing effectiveness. This study specifically centered on marketing communication, service quality, relationship marketing and E-marketing strategies, out of the numerous competitive marketing strategies adopted by ride-hailing service companies. Hence, future studies should explore the influence of other marketing strategies such as focus strategy (niche marketing), search engine marketing, and logistics management in the context of ride-hailing services to provide additional insight to operators and researchers.

Conflict of Interest: The authors are in complete agreement about the contents and structure of the paper; and hence declare absolutely no conflict of interest.

Acknowledgements: We acknowledge the contributions of all existing scholars whose scholarly publications were duly cited in this paper. We appreciate the ride-hailing service passengers who created time to participate in the questionnaire survey, thereby providing data that facilitated the successful completion of this research.

Research Funding: This research was carried out without external funding in any guise or form.

\section{References}

Adam, A. M. (2020). Sample size determination in survey research. Journal of Scientific Research and Reports, 4, 90-97

Akinitire, G., Segundayo, P., \& Oluwatobi, R. (2018). Marketing strategies and the performance of small and medium-scale enterprises in Lagos State, Nigeria. European Journal of Advanced Research in Economics, 8(4), 105-115

Alhawamdeh, Z. M. (2021). The implementation of the marketing communication mix using internet platforms on Turkish Cypriot Hotels. International Journal of Business and Management, 14(3), 124-124.

Ang'asa, M. N. (2017). Effect of competitive strategies adopted by ride-hailing companies in Nairobi, Kenya to sustain competitive advantage in the taxi industry [An MBA Thesis, University of Nairobi]

Anne, M. W. (2020). Digital marketing strategies and the marketing performance of top 100 small and medium enterprises (SMESs) in Kenya. International Journal of Research in Management \& Business Studies, 7(3), 26-31 
Ataman, M. B., Van Heerde, H. J., \& Mela, C. F. (2017). The long-term effect of marketing strategy on brand sales. Journal of Marketing Research, 47(5), 866-882.

Christa, U., \& Kristinae, V. (2021). The effect of product innovation on business performance during COVID 19 pandemic. Uncertain Supply Chain Management, 9(1), 151-158.

Ebitu, E. T. (2016). Marketing strategies and the performance of small and medium enterprises in Akwa Ibom State, Nigeria. British Journal of Marketing Studies, 4(5), 51-62

Etim, G. S., James, E. E., Arikpo, N. N. \& Okeowo, V. O. (2021). E-marketing strategies and performance of small and medium-sized enterprises: A new-normal agenda. Journal of Business and Management Studies, 3(2), 162-172

Etuk, A., Anyadighibe, J. A., James, E. E. \& Mbaka, R. (2021). Service quality and passengers' loyalty of public transportation companies. British Journal of Management and Marketing Studies, 4(4), 82-98

Gaber, H. R., \& Elsamadicy, A. M. (2021). What drives customers to continue using ridesharing apps during the COVID-19 pandemic? The case of Uber in Egypt. Cogent Business \& Management, 8(1), 1-21.

Hänninen, N., \& Karjaluoto, H. (2017). The effect of marketing communication on business relationship loyalty. Marketing Intelligence \& Planning, 4(2), 78-91

Haran, J., \& Yusuf, I. (2013). Marketing strategies and corporate performance: Exploring the relationship. International Journal of Service Industry Management, 10(3), 271-281

Husnain, M., \& Akhtar, M. W. (2015). Relationship marketing and customer loyalty: Evidence from banking sector in Pakistan. Global Journal of Management and Business Research: E-Marketing, 15(10), 1-14.

Hussain, R., Al Nasser, A., \& Hussain, Y. K. (2015). Service quality and customer satisfaction of a UAE-based airline: An empirical investigation. Journal of Air Transport Management, 42, 167-175.

Iddris, F., \& Ibrahim, M. (2015). Examining the relationships between e-Marketing adoption and Marketing Performance of Small and Medium Enterprises in Ghana. Journal of Marketing and Consumer Research, 10, 160-169.

Izogo, E. E. (2017). Customer loyalty in telecom service sector: the role of service quality and customer commitment. The TQM Journal, 8(2), 20-29

Korir, E. J. (2020). E-marketing strategies and performance of registered rated hotels in Nakuru County [MBA thesis, Kenyatta University, Kenya]

Lampe, I., Alatas, R., Orynka, N., \& Saputra, G. B. (2021). Local online courier and ridehailing service social media marketing. Komunikator, 13(1), 66-77.

Luxton, S., Reid, M., \& Mavondo, F. (2015). Integrated marketing communication capability and brand performance. Journal of Advertising, 44(1), 37-46.

Man, C. K., Ahmad, R., Kiong, T. P., \& Rashid, T. A. (2019). Evaluation of service quality dimensions towards customers' satisfaction of ride-hailing services in Kuala Lumpur, Malaysia. International Journal of Recent Technology and Engineering, 7(5), 102109 
Mustapha, B. (2017). Effects of marketing strategies on performance of small scale businesses in Maiduguri Metropolitan, Borno State Nigeria. Journal of Marketing and Consumer Research, 3(1), 1-6

Nwulu, C. S., \& Asiegbu, I. F. (2015). Advancement inclination behaviors and university academic staff patronage of deposit money banks in Port Harcourt. International Journal of Research in Business Studies and Management, 2(6), 94-104.

Odigbo, B. (2018). Mastering research: Developing countries' challenges ( ${ }^{\text {st }}$ Ed.). Enugu: Rhyce Kerex Publishers

Pappas, N. (2016). Marketing strategies, perceived risks, and consumer trust in online buying behaviour. Journal of Retailing and Consumer Services, 29, 92-103.

Payne, A., \& Frow, P. (2017). Relationship marketing: Looking backwards towards the future. Journal of Services Marketing, 7(2), 49-61

Perri, J. (2021). Uber vs. Lyft: Who's tops in the battle of U.S. rideshare companies. Retrieved from: https://secondmeasure.com/datapoints/rideshare-industry-overview/

Precedence Research (2021). Ride sharing market size to worth around US\$ 344.4 bn by 2030. Retrieved from: https://www.globenewswire.com/newsrelease/2021/09/28/2304958/0/en/Ride-Sharing-Market-Size-to-Worth-Around-US344-4-Bn-by-2030.html

Purcarea, E. V. (2019). The impact of marketing strategies in healthcare systems. Journal of Medicine and Life, 12(2), 93-108

Sheikh, A. A., Shahzad, A., \& Ishaq, A. K. (2017). The growth of e-marketing in businessto-business industry and its effect on the performance of businesses in Pakistan: Marketing success. International and Multidisciplinary Journal of Social Sciences, 6(2), 178-214.

Statistica (2021). Ride-hailing \& taxi. Retrieved from: https://www.statista.com/outlook/mmo/mobility-services/ride-hailingtaxi/worldwide

Steinhoff, L., Arli, D., Weaven, S., \& Kozlenkova, I. V. (2019). Online relationship marketing. Journal of the Academy of Marketing Science, 47(3), 369-393.

Suhud, U. (2021). Influence of social media marketing, electronic word of mouth and consumer engagement to brand loyalty in Indonesia Grab Company. International Journal of Business and Social Science Research, 2(2), 16-26.

Tong, S., Luo, X., \& Xu, B. (2020). Personalized mobile marketing strategies. Journal of the Academy of Marketing Science, 48(1), 64-78.

Wakhu, P., \& Bett, S. (2019). Effect of competitive strategies on performance of Uber Online Taxi firm in Nairobi, Kenya. International Journal of Current Aspects, 3(4), 80-92. Retrieved from: http://journals.ijcab.org/journals/index.php/ijcab/article/view/48

Yalo, M. I., Enimola, D. J. \& Nafiu, A. T. (2019). Effects of marketing strategies on the performance of small and medium-scale enterprises in Kogi State. International Journal of Research and Innovation in Social Science, 3(2), 445-451 